Artigo

\title{
Os Direitos Humanos e as Mulheres: a escola pode civilizar?
}

\author{
Los Derechos Humanos y la Mujer: \\ ¿puede la escuela civilizarse?
}

\author{
Human rights and Women: \\ can the school civilize?
}

Droits de Humains et femmes:

l'école peut-elle être civilisée?

\footnotetext{
${ }^{1}$ Graduado em Educação Física pelas Faculdades Integradas de Guarulhos, Guarulhos, SP, Brasil, Mestre em Educação pela Pontifícia Universidade de São Paulo, São Paulo, Brasil, e doutor em Ciências Sociais pela Universidade Estadual Paulista "Júlio de Mesquita Filho", Araraquara, SP, Brasil. Atualmente é professor da Universidade Cruzeiro do Sul, São Paulo, SP, Brasil. 
Resumo

Abstract
A luta por direitos concretos nunca se esgotará em uma sociedade marcada pela desigualdade. A exploração econômica e as diferentes formas de opressão que produzem e reproduzem todas as formas de desigualdade criam grupos privilegiados, que gozam de todos os direitos possíveis, e outros que mal conhecem os seus direitos, ou, ainda pior, mesmo os conhecendo, ainda, assim, não veem seus direitos serem respeitados. A violência é, indiscutivelmente, um instrumento potente para o estabelecimento da ordem, para a conquista e manutenção do poder. As mulheres têm seus direitos básicos afetados, por exemplo, o direito de ir vir sem riscos de ser molestada; o direito de vestir-se como quiser; o direito de poder dizer não aos desejos de qualquer homem, inclusive se for seu parceiro; o direito de não ter o valor de seu trabalho diminuído em comparação ao trabalho de um homem; o direito de ser protegida fisicamente de ex-companheiro, potencial assassino que a ameaça reiteradamente; o direito a usufruir do transporte público sem sofrer qualquer forma de assédio; enfim, essa lista poderia ser estendida por infinitos itens que fazem parte de todas as mulheres brasileiras, e o que é ainda mais grave, desde sua infância, quando boa parte das mulheres sofrem algum tipo de abuso ou, ao menos, de tentativa de abuso sexual, desde formas mais sutis até as mais perversas, grosseiras. Discute-se aqui a educação como elemento fundamental para se problematizar os direitos humanos, trazendo à tona elementos que dão destaque à invisibilidade que os direitos, quando pensado a partir das vidas das mulheres, apresentam.

Palavras-Chave: Direitos Humanos; Violência Contra a mulher; Direitos das Mulheres; Escola e Direitos Humanos; Escola e Relações de Gênero.

The fight for concrete rights will never be exhausted in a society marked by inequality. Economic exploitation and the different forms of oppression that produce and reproduce all forms of inequality create privileged groups that enjoy all possible rights, and others who barely know their rights, or even worse, even knowing them, still do not see their rights respected. Violence is unquestionably a powerful instrument for establishing order, for gaining and maintaining power. Women have their basic rights affected, for example, the right to come without risk of being molested; the right to dress as one wishes; the right to be able to say no to the wishes of any man, even if he is his partner; the right not to have the value of his work diminished in comparison to the work of a man; the right to be physically protected from an ex-partner, a potential murderer who repeatedly threatens him; the right to enjoy public transportation without suffering any form of harassment; in short, this list could be extended by endless items that are part of all Brazilian women, and what is even more serious, since their childhood, when most women suffer some kind of abuse or, at least, attempted sexual abuse, from more subtle forms to the most perverse, gross. Education is discussed here as a fundamental element to problematize human rights, bringing out elements that highlight the invisibility that rights, when thought from the lives of women, present. 
Keywords: Human Rights; Violence Against Women; Women's Rights; School and Human Rights; School and Gender Relations.

Resumen

\section{Resumé}

La lucha por derechos concretos nunca se agotará en una sociedad marcada por la desigualdad. La explotación económica y las diferentes formas de opresión que producen y reproducen todas las formas de desigualdad crean grupos privilegiados que disfrutan de todos los derechos posibles, y otros que apenas conocen sus derechos, o peor aún, incluso conociéndolos, todavía no ven sus derechos respetados. La violencia es, sin duda, un poderoso instrumento para establecer el orden, para ganar y mantener el poder. Las mujeres ven afectados sus derechos básicos, por ejemplo, el derecho a venir sin riesgo de ser molestadas; el derecho a vestirse como se desee; el derecho a poder decir no a los deseos de cualquier hombre, aunque sea su pareja; el derecho a que el valor de su trabajo no disminuya en comparación con el trabajo de un hombre; el derecho a ser protegido físicamente de su ex pareja, un asesino en potencia que lo amenaza repetidamente; el derecho a disfrutar del transporte público sin sufrir ningún tipo de acoso; por último, esta lista podría ampliarse con infinidad de elementos que forman parte de todas las mujeres brasileñas, y lo que es más grave aún, desde su infancia, cuando buena parte de las mujeres sufren algún tipo de abuso o, al menos, intento de abuso sexual, desde las formas más sutiles hasta las más perversas y groseras. La educación se discute aquí como un elemento fundamental para problematizar los derechos humanos, sacando a la luz elementos que ponen de relieve la invisibilidad que los derechos, cuando son pensados desde la vida de las mujeres, presentan.

Palabras Clave: Derechos Humanos; Violencia Contra la Mujer; Derechos de la Mujer; Escuela y Derechos Humanos; Escuela y Relaciones de Género.

La lutte pour des droits concrets ne sera jamais épuisée dans une société marquée par l'inégalité. L'exploitation économique et les différentes formes d'oppression qui produisent et reproduisent toutes les formes d'inégalité créent des groupes privilégiés qui jouissent de tous les droits possibles, et d'autres qui connaissent à peine leurs droits, ou pire, qui les connaissent même, ne voient toujours pas leurs droits respectés. La violence est incontestablement un instrument puissant pour établir l'ordre, pour gagner et maintenir le pouvoir. Les femmes voient leurs droits fondamentaux affectés, par exemple, le droit de venir sans risquer d'être molestées ; le droit de s'habiller comme on le souhaite ; le droit de pouvoir dire non aux souhaits de tout homme, même s'il est son partenaire ; le droit de ne pas voir la valeur de son travail diminuée par rapport au travail d'un homme; le droit d'être physiquement protégées de leur expartenaire, un meurtrier potentiel qui le menace à plusieurs reprises; le droit de jouir des transports publics sans subir aucune forme de harcèlement; enfin, cette liste pourrait être complétée par une infinité d'éléments qui font partie de toutes les femmes brésiliennes, et ce qui est encore plus grave, depuis leur 
enfance, où une bonne partie des femmes subissent une forme quelconque d'abus ou, du moins, de tentative d'abus sexuel, des formes les plus subtiles aux plus perverses et grossières. L'éducation est abordée ici comme un élément fondamental pour problématiser les droits de humains, en faisant ressortir les éléments qui mettent en évidence l'invisibilité que présentent les droits, lorsqu'ils sont pensés à partir de la vie des femmes.

Mots-Clés: Droits Humains; Violence Contre les Femmes; Droits des Femmes; École et Droits Humains; École et Relations Entre Genres. 


\section{Uma Introdução}

A luta por direitos concretos jamais se esgotará em uma sociedade de classes. A dinâmica social estabelecida por uma sociedade desigual vai, passo a passo, dilacerando o tecido social. À exploração econômica, constitucionalmente garantida pelo Estado, se juntam outras formas de opressão baseadas em diferentes processos sociais e culturais.

Sabe-se que em uma sociedade de classes, que se apoia em outras formas de opressão para potencializar a exploração, como apontou Heleieth Saffioti (2004), quando criou a noção de nó, a desigualdade produzirá um raquítico exercício dos direitos sociais, políticos e civis por esses grupos atingidos, que na realidade vivem como se fossem cidadãos de segunda classe, quando comparados aos grupos hegemônicos, que praticam o pleno exercício da cidadania.

A combinação das diferentes formas de opressão e de exploração levam à produção e reprodução permanente da desigualdade. Seja ela por razões econômicas, como nas relações de classes, ou ainda por questões identitárias, como nas relações de gênero, de raça-etnia, de sexualidade, de moradia, de variação linguística, entre outras.

Evidentemente que as forças que atuam por meio das relações sociais que produzem e reproduzem a desigualdade não se dão isoladamente, como poderia parecer pela afirmação anterior. Essa distinção é apenas um recurso explicativo, pois na vida concreta elas se encontram em sinergia, e se potencializam.

As ideologias racista e patriarcal, por exemplo, não atuam isoladamente, ao contrário, se potencializam na relação entre elas e entre a ideologia capitalista, que se vale das posições de inferioridade a que esses grupos são expostos, para aumentar ainda mais seu grau de mais-valia, em outras palavras, seu grau de exploração.

Quanto maior o nível de exploração a que um grupo está exposto, mais vulnerável será sua situação concreta, pois os impactos se darão em todas as esferas da vida: terá menor chance de acesso a uma educação de qualidade; terá de se sujeitar aos subempregos, aos bicos, sem nenhuma proteção social para hoje e nem para o futuro; trabalhará no máximo para alguma refeição para sua família; não terá acesso a nenhum tipo de bem, seja material, como uma moradia digna, ou imaterial, como acesso a programas culturais. Evidentemente que, diante deste quadro, há que se reconhecer que nem mesmo os direitos básicos estão garantidos a significativas parcelas da população.

Desta forma, mulheres negras, pobres, sem escolaridade, abandonadas pelo pai de seus filhos, encontram-se em situação limite quanto à capacidade de subsistir e de garantir a subsistência de seus filhos. Assim, se submeterá às piores condições de trabalho para garantir a sobrevivência dela e de seus filhos.

Para Heleieth Saffioti (2004), é impossível a luta contra apenas uma das formas de produção de opressão e exploração, para tanto é preciso desatar esse nó capitalismo-patriarcado-racismo que potencializa a precarização da vida para um grande contingente da população.

Em outras palavras, é preciso atacar em todas as frentes. Assim, colocar-se contra o modelo econômico, marcado pela primazia dos interesses do mercado e dos capitalistas contra os interesses dos povos, contra os interesses da imensa classe de pessoas que vivem do próprio trabalhado, que se constitui na gigantesca maioria da população; defender um modelo de Estado que possa significar um avanço do ponto de vista das políticas sociais que atendam às 
necessidades básicas da população como: a defesa intransigente da ampliação da capacidade de atendimento do SUS, da manutenção e ampliação dos programas de renda mínima, da criação de programas habitacionais à população mais vulnerável e às camadas de trabalhadores sem qualificação profissional, desenvolvimento de programas de cultura e lazer acessível à toda população trabalhadora, além de grandes investimentos nos programas escolares, de tempo integral e de qualidade para toda a população.

Essas ações precisam estar conectadas com os movimentos sociais, com os coletivos identitários, que vêm produzindo resistência aos processos que os inferioriza. Por vezes esses movimentos atuam de forma isolada e, portanto, desconectado das ricas e complexas determinações que incidem sobre as formas de vida do conjunto da população trabalhadora.

Não se pode perder de vista, que todo e qualquer coletivo não é homogêneo, ao contrário, é heterogêneo e complexo, acolhe diferentes matrizes de pensamento que resultam igualmente em diferentes estratégias, em diferentes formas de enfrentamento, e, principalmente, em diferentes objetivos.

O pensamento feminista negro, por exemplo, só surge pela ausência de suas demandas em um suposto "feminismo" universal. É partir da visibilidade das questões postas pelas mulheres negras que se pôde perceber a natureza do feminismo de então, como uma teoria e um movimento produzidos por mulheres brancas, pertencente às classes médias.

Ocorre a mesma diversidade de posições dentro dos outros movimentos sociais ou outros coletivos. Os interesses estão enraizados na vida social de cada um de seus membros, e suas demandas são, portanto, semelhantes por um lado e divergentes por outro (Silva, 2009). As demandas por questões econômicas, típicas das classes sociais, são sentidas e/ou percebidas de maneira distintas pelos sujeitos imbricados em um certo coletivo. As classes sociais apresentam em seu interior camadas sociais, caracterizadas pela posição que os indivíduos têm no processo econômico. Por exemplo, a diferença entre os trabalhadores que possuem uma formação superior, e, assim, assumem postos de trabalho com melhores remuneração, que proporciona a eles um certo padrão de consumo e de acesso a bens culturais, e aqueles que não possuem escolaridade alguma, e que estarão gravitando em torno de subempregos, dificultam sua identificação como pertencentes ao mesmo grupo social. Desta forma, os interesses que estarão em jogo num dado movimento social, como o feminista, não será universal, pois será recortado por diferentes interesses de classes, entre outros (Silva, 2007).

Assim, essa heterogeneidade pode produzir a fragmentação dos movimentos populares, de forma a exigir que esses atores passem a se desdobrar em diferentes movimentos de seus interesses, o que certamente promove um desperdício de energia e enfraquece a pressão a ser continuamente exercida contra as forças que dominam o Estado e suas políticas. A visão de totalidade é uma questão de grande importância para as lutas de todos os segmentos sociais subjugados, pois cria a possibilidade de potencialização dos movimentos e das lutas sociais.

Em qualquer sociedade de classes há sempre a contradição entre privilégios e direitos, entre privilegiados e aqueles privados de certos direitos. 0 privilégio é o direito de usufruir de certas condições, de dispor de certas coisas, que outros estão impedidos de o fazerem concretamente. 0 direito, tal como o conhecemos, tem um caráter formal, portanto, abstrato, sintetizado na frase: "a lei é para todos". Mas sabe-se que se trata apenas de uma retórica, pois na vida concreta, os privilégios e os privilegiados continuam a existir, e não há sinais de que esta situação poderá se modificar, a menos que haja uma grande mobilização social a fim de pressionar o poder público, que são os maiores defensores da manutenção dos privilégios. 
No caso das mulheres, seus direitos básicos são visivelmente afetados: o direito de ir vir sem riscos de ser molestada; o direito de vestir-se como quiser; o direito de poder dizer não aos desejos de qualquer homem, inclusive se for seu parceiro; o direito de não ter o valor de seu trabalho diminuído em comparação ao trabalho de um homem; o direito de ser protegida fisicamente de ex-companheiro, potencial assassino que a ameaça reiteradamente; o direito a usufruir do transporte público sem sofrer qualquer forma de assédio; enfim, essa lista poderia ser estendida por infinitos itens que fazem parte de todas as mulheres brasileiras, e o que é ainda mais grave, desde sua infância, quando boa parte das mulheres sofrem algum tipo de abuso ou, ao menos, de tentativa de abuso sexual, desde formas mais sutis até as mais perversas, grosseiras.

Os direitos são determinados, em última instância, pela Constituição Federal. Entretanto, o cumprimento de suas metas passa pela vida concreta e pela falta de mecanismos para se garantir o direito de todas as pessoas, independentemente de qualquer marca identitária e ou de condição econômica.

\section{A Luta das Mulheres e os Direitos Humanos}

Desde há décadas, as mulheres vêm alcançando cada vez mais um maior protagonismo em suas vidas. Primeiramente, em função do acesso de mulheres das classes médias ao trabalho, visto que as pobres sempre trabalharam -- embora esse fenômeno seja marcado pela invisibilidade --, não mais se sujeitando inteiramente a uma posição secundária diante do pai ou do companheiro, o que já lhes dá um certo grau de autonomia e de liberdade. Um segundo e importante aspecto é seu desempenho escolar/educacional, que se mostra superior ao dos homens, o que as leva a uma melhor compreensão da realidade, a melhores argumentos, o que as ajuda a pôr em xeque algumas determinações machistas que lhes soam como privilégio. E finalmente, há um processo de empoderamento, estimulado pela visibilidade dos movimentos de mulheres, em suas diversas faces, e pelos movimentos negros e LGBTTQI+ (Silva, 2007, 2006; Silva \& Ortolano, 2015). Elas passam, então, a sentir-se mais à vontade para enfrentar ou resistir às lógicas da dominação masculina. Passam a ser menos dissimuladas, trocando as formas mais sutis de resistência por outras mais explícitas.

A violência continua sendo uma ferramenta privilegiada para a garantia da ordem, seja para a conquista ou para a manutenção da posição de poder. Ou seja, ela é utilizada não apenas quando a ordem estabelecida se mostra ameaçada, mas também para renovar a dominação.

Para Teles e Melo (2003: 23):

A violência é uma das mais graves formas de discriminação em razão de sexo/gênero. Constitui violação dos direitos humanos e das liberdades essenciais, atingindo a cidadania das mulheres, impedindo-as de tomar decisões de maneira autônoma e livre, de ir e vir, de expressar opiniões e desejos, de viver em paz em suas comunidades; direitos inalienáveis do ser humano. É uma forma de tortura que, embora não seja praticada diretamente 
por agentes do Estado, é reconhecida como violação dos direitos humanos desde a Conferência Mundial de Direitos Humanos realizada em Viena (Áustria) em 1993, isso porque cabe ao Estado garantir segurança pública, inclusive da população feminina. É um fenômeno que atinge mulheres de diferentes classes sociais, grupos étnicos, posições econômicas e profissionais.

A violência contra a mulher continua se mostrando um instrumento recorrente no processo de afirmação da dominação masculina. 0 conceito de violência contra a mulher, aqui tomado, não a toma apenas como a ruptura da integridade da vítima, seja ela física, psíquica, sexual ou moral, avança-se a uma concepção ligada aos direitos humanos.

Desde 1993, a violência contra a mulher passa a ser reconhecida como um direito humano pela Conferência Mundial de Direitos Humanos, promovida pela Organização das Nações Unidas (ONU), em Viena. O Estado, neste caso, passa a ser responsável pela proteção e segurança da vida das mulheres (Teles \& Melo, 2003).

As políticas de direitos humanos, até o momento acima citado, traziam referências apenas dos direitos civis e políticos, pensando apenas nos agentes do Estado. Não se tomava ciência das necessidades das mulheres que são espancadas ou assassinadas por seus companheiros ou excompanheiros, além daquelas que são mutiladas em função de abortos clandestinos, ou ainda que sofrem com estupros e abusos sexuais, recorrentes ou não, como vítima de pais, padrastos, tios, avós, amigos da família entre outros (Teles \& Melo, 2003).

A ONU, em 1979, portanto, antes da Conferência mencionada, aprovou a convenção que trazia como proposta a eliminação de todas as formas de discriminação contra a mulher. Esta proposta foi assinada pelo governo brasileiro, em 1984, mesmo que com algumas reservas, passou a ser um importante instrumento na luta contra a violência praticada contra as mulheres (Teles \& Melo, 2003). Pelo documento, a discriminação contra a mulher significa:

toda distinção, exclusão ou restrição baseada no sexo e que tenha por objetivo ou resultado prejudicar ou anular o reconhecimento, gozo, exercido pela mulher, independentemente de seu estado civil, com base na igualdade do homem e da mulher, dos direitos humanos e das liberdades fundamentais nos campos políticos, econômico, social, cultural e civil ou em qualquer outro campo (Teles \& Melo, 2003: 35).

É importante o reconhecimento dos aspectos culturais sobre a vida das mulheres. Em certas culturas, as mulheres podem ser submetidas a situações de violência, que, entretanto, são consideradas normais para suas culturas. A naturalização da inferioridade das mulheres em relação aos homens, ou o fato de em certas regiões africanas as mulheres terem sua genitália mutilada, encontram explicações em elementos da própria cultura, como, em certos casos, a própria religião. 0 feminicídio ainda é visto como um fenômeno natural, em certas sociedades, onde não se imputa responsabilidade ao criminoso, o que o torna invisível à própria sociedade, como se nada tivesse acontecido, impedindo, desta forma, que surjam políticas públicas eficazes para o enfrentamento deste gravíssimo problema social (Saffioti, 2004).

O poder do macho o induz a ser violento e mais violência é necessária para preservar este poder sempre que ele sofre qualquer ameaça. Não importa que a ameaça seja concreta ou que ela exista apenas na fantasia do macho. Sempre que ele se sentir ameaçado, poderá, legitimamente, conforme a ideologia machista, fazer uso da força física, chegando ao extermínio (Saffioti, 2000: 58). 
"Em briga de marido e mulher não se mete a colher", ditado este que colocava as mulheres em uma grave situação de risco, pois a imobilização dos grupos sociais mais próximos, como a família e a vizinhança, agravava sua segurança. Atualmente, a "Central de Atendimento à Mulher - Ligue 180" pode ser acionada por qualquer pessoa, mesmo que seja desconhecida. Evidentemente que esse importante serviço não resolve todas as questões e consequências da violência praticada contra as mulheres, mas permitir que terceiros possam denunciar um caso de violência contra a mulher, o que já é um grande avanço.

Para Saffioti e Almeida (1995: 29-30), a violência estará sempre presente nas relações patriarcais de gênero, pois a primeira, na visão das autoras, é constitutiva da ordem social:

O gênero informado pela desigualdade social, pela hierarquização e até pela lógica da complementariedade traz embutida a violência. Não faz sentido, por via de consequência, separar a violência estrutural de outras que, por oposição, se poderiam denominar conjunturais. [...] A violência de classe, gênero e de raça/etnia, ao contrário, é conditio sine qua non para a instauração e preservação da hegemonia destes agregados.

No Brasil, a violência contra a mulher está presente também em ações políticas, na promulgação de leis; é o caso da demissão, ou ameaça, de mulheres que se casam, e que, obviamente, podem vir a engravidar. Nos debates políticos, durante a elaboração da constituição brasileira de 1988, ao se propor a extensão do direito da licença maternidade às mulheres de 3 para 4 meses, houve uma ação reacionária. Colocando-se como preocupados com a situação das mulheres, fazia-se uma ameaça velada, ao dizer que elas seriam ainda mais discriminadas, enfrentando maiores dificuldades para se empregar, para se manter no emprego, ou afetaria até mesmo sua carreira. Naquele momento, certamente, a possibilidade da gravidez passou a ser um pesadelo para as mulheres trabalhadoras (Vaz, 2005, 2012).

A igualdade expressa nos direitos humanos exige o fim de qualquer forma de discriminação. Do ponto de vista das relações de gênero, mulheres e homens têm o mesmo direito ao gozo pleno. A igualdade, por vezes, exige um tratamento idêntico a homens e mulheres, outras vezes exige um tratamento distinto, para que se corrija algumas injustiças históricas que estão consolidadas na cultura. É certo afirmar que é discriminatório tratar diferentes como se fossem idênticos, pois isso pode ampliar a desigualdade. Como corrobora Alda Facio (2011), quando afirma que a igualdade entre mulheres e homens pode ser definida como um trato idêntico ou diferenciado, mas que não acabe em forma alguma de discriminação contra as mulheres, apenas por serem mulheres.

A parte mais visível da violência contra a mulher é o seu fim, o seu assassinato, o chamado feminicídio. Ele é a linha final de violência contra as meninas e mulheres, que sofrem, muitas vezes em silêncio, com as artimanhas e crueldade de seus algozes. É o processo contínuo de violação dos direitos humanos das mulheres que, em alguns casos, chega-se à morte, ao feminicídio (Ríos, 2017).

O feminicídio é o resultado de uma forma de compreender o mundo, o patriarcado, que torna possível a opressão, a discriminação, a exploração e a, consequente, exclusão de meninas e mulheres de suas atividades sociais como cidadã legítima que são. Uma cultura que legitima a desvalorização das mulheres, que permite que sejam hostilizadas e degradadas, que se exponham à arbitrariedade e, que sejam com frequência vítimas da impunidade judicial, só poderá criar uma sociedade em que as mulheres tendem a ocupar os piores postos desta sociedade, produzindo e reproduzindo a desigualdade (Ríos, 2017). 
Os feminicídios parecem ser mais acentuados em situações sociais onde os direitos humanos são violados com mais frequência, o que torna essas situações mais agudas. Há uma articulação destas questões com outras questões de ordem social e econômica, como a extrema marginalização e exclusão social, jurídica e política (Ríos, 2017).

Saffioti (1999) acredita que a pobreza e o uso de drogas ou álcool, possam desencadear a violência, mas não pode ser entendido como uma explicação única e definitiva. Afinal ricos também praticam esse tipo de violência, há, inclusive, formas de violência muito específica de setores ricos da sociedade, a ameaça da perda do patrimônio e, em especial, do estilo de vida.

Elisabeth Maier (1992) afirma que ao se entender que o Estado tem responsabilidade na luta pela erradicação da violência contra a mulher, e vendo-a como violação dos direitos humanos, a Comissão Interamericana de Mulheres da Organização dos Estados Americanos redigiu um anteprojeto recomendando o desenvolvimento de uma Convenção Interamericana para prevenir, punir e erradicar a violência contra a mulher. Esta se concretizou na Conferência de Belém do Pará, em 1994.

A Conferência de Belém do Pará, a The Convention on the Elimination of All Forms of Discrimination against Women, a Conferência de Beijing e Beijing +10 , trata a violência contra meninas e mulheres como uma forma de exercício do domínio, do controle e da opressão exercida pelos homens. As mulheres, ao serem tratadas como objetos, estão sujeitas à dominação masculina, mesmo que em diferentes graus, cada uma de acordo com o contexto em que vive. Isso reforça as formas de maltrato que ocorrem no cotidiano visível e invisível, e é realizado por parentes, companheiros, amigos e desconhecidos, por autoridades, governantes, funcionários, dirigentes entre outros (Lacarde, 2017).

Em qualquer situação de sua vida cotidiana, as meninas e as mulheres estão sempre correndo riscos. A própria casa é um lugar inseguro, pois a violência doméstica e a familiar podem estar latentes. Se falarmos na esfera pública, como a escola, o trabalho, as ruas, a diversão, os encontros culturais, o transporte público, os caminhos, os bairros, os parques, são sempre possíveis pontos de insegurança. Acrescente-se a isso, o período do dia, o horário pode tornar aparentemente mais segura ou menos segura uma determinada ação (Lacarde, 2017).

As meninas, as adolescentes, as jovens, as mulheres maduras, as idosas, podem ser objeto de violência sexual, física, emocional, moral, verbal, patrimonial e simbólica. Em uma sociedade patriarcal, que ainda legitima a dominação masculina, esta violência pode até parecer ser natural, com as mulheres sendo consideradas agentes provocadoras dessas violências; o que por vezes libera, assim, seus algozes de qualquer forma de responsabilização.

A patologização do algoz não facilita a resolução do problema, pois oculta razões ligadas a estrutura social, patriarcal, que produz as condições concretas para que se mantenha a dominação, masculina. É a partir desse entendimento que se poderá conseguir avançar na alteração da realidade para todas as mulheres (Lacarde, 2017).

Como a sociedade, de certo, ainda tolera a violência praticada por companheiros contra as mulheres, não estranham o fato de homens exercerem, pela força, sua vontade contra as mulheres, ela acaba por dificultar o surgimento de uma virilidade doce e sensível, que seria mais adequada ao desfrute e ao compartilhamento. Essa tolerância à agressividade dos homens contra as mulheres prejudica tanto a formação das mulheres, quanto a deles próprios, visto que serão sempre seres incompletos como ser humano, não desenvolvendo seu lado amoroso e afetivo (Saffioti, 1999). 
Pesquisadoras de vários países, a partir da constatação da condição de inferioridade das mulheres, em maior ou menor grau, assinalaram as raízes patriarcais dos direitos humanos e sua implicação para as mulheres. Elas colocam a questão da exclusividade masculina no desenvolvimento dos conteúdos dos direitos humanos, lembremos que este documento tem início como Declaração dos Direitos do Homem e do cidadão (Maier, 1992).

A partir da segunda metade do século XX, como fruto das lutas empreendidas pelos direitos humanos do gênero feminino, as mulheres foram atendidas, ao menos na linguagem, que traz em seu Artigo II:

Todo ser humano tem capacidade para gozar os direitos e as liberdades estabelecidos nesta Declaração, sem distinção de qualquer espécie, seja de raça, cor, sexo, idioma, religião, opinião política ou de outra natureza, origem nacional ou social, riqueza, nascimento, ou qualquer outra condição. (ONU, 2017: 4). (Grifo meu)

Os direitos humanos nascem da necessidade e das lutas por vida com dignidade, eles trazem um conjunto de pautas éticas, com projeções jurídicas. Eles são historicamente elaborados, conforme as diferentes necessidades de certos grupos sociais, e vão se acumulando, e sendo paulatinamente aceitos pela maioria das nações. Assim, trata-se um acervo histórico consagrado na luta dos povos por dignidade em termos políticos, econômicos, sociais e ambientais (Maier, 1992).

Para a mulher, a satisfação da vida, educação e trabalho não significa que esteja livre da violência doméstica, da perseguição sexual e de jornadas de trabalho de 20 horas. A ausência de guerra não leva paz à sua casa. A ausência de um regime autoritário e ditatorial no país não significa liberdade pessoal para a mulher que pode passar toda a vida sob as botas do pai, do esposo ou mesmo de um filho, ainda em um regime democrático (Facio, 1991 citado por Maier, 1992: 38) (Tradução minha).

As mulheres têm sua dignidade fortemente afetada quando a agressão sexual e doméstica é praticada contra si. Esta violência é invisível do ponto de vista público, portanto, até mesmo pelos defensores dos direitos humanos ela chega a ser ignorada. A violência contra as mulheres é uma das manifestações mais violadas da Declaração universal de direitos humanos, em especial em seu artigo $3^{\text {o }}$ "Todo ser humano tem direito à vida, à liberdade e à segurança pessoal", e no $5^{\circ}$ "Ninguém será submetido à tortura, nem a tratamento ou castigo cruel, desumano ou degradante" (Maier, 1992).

O fato da sociedade patriarcal separar o espaço público do espaço privado, é um dos motivos pelo qual se dificulta o reconhecimento deste tipo de violência como uma violação dos direitos humanos. Ao se conceber esses espaços sociais como íntima e dialeticamente relacionados, sem distinções e nem privilégios, teremos de elaborar novas noções e novas práticas sociais, onde os direitos humanos poderão ser de fato estendidos a todas e todos (Maier, 1992).

Os direitos humanos não são de fato percebidos por todas as pessoas na mesma dimensão. Sua consideração varia segundo as classes sociais, as raças/etnias, os gêneros e outras formas identitárias, e há diferença mesmo dentro de cada uma das categorias acima listadas. Há processos em movimento que avançam na direção de configurar os direitos humanos para a população feminina, como ocorre na saúde, na educação, na questão da violência, nas práticas jurídicas, etc. Uma espécie de cidadania ampliada, que contemple e reconheça os direitos 
humanos também para os pobres, para os negros, para as mulheres, entre outros (Saffioti, 1999, 2004; Silva, 2007; Silva e D'Addio, 2012).

Segundo Elizabeth Maier (1992), os direitos humanos possuem três características primordiais: 1. São inalienáveis, não se vende; 2. São imprescritíveis, jamais se expiram; e 3. São indivisíveis, não se pode privilegiar uns em detrimento de outros. É a terceira característica que obriga, eticamente, a defesa de todos os direitos humanos, com a mesma intensidade.

Durante o decênio da Mulher (1975-1985), estabelecido pela ONU, mais precisamente em 1979, aprovou-se pelas nações membros a "Convenção sobre a eliminação de todas as formas de discriminação contra a mulher". É um documento sobre os direitos humanos, mas se dedica inteiramente às mulheres. Resultado das lutas das mulheres, esse documento é um instrumento internacional completo e avançado, mesmo que ignorando a questão do controle do corpo, incorpora e sistematiza demandas que destacam a eliminação da discriminação e das condições econômicas, educativa, do trabalho doméstico, da cultural, da saúde, das questões rurais e políticas (Maier, 1992).

A função social da maternidade, também está contemplada no documento, e responsabiliza a ambos os progenitores pela criação dos filhos e no papel de desenvolver uma cultura de relações simétricas de gênero. Defende, ainda, o compartilhamento do protagonismo por ambos (Maier, 1992).

Tornou-se um marco, um acontecimento fundamental, o reconhecimento de que a violência contra as mulheres é uma violação dos direitos humanos. Esse fato repercute internacionalmente, passa a incorporar a vida cotidiana e seus desdobramentos também como direitos humanos. Para que o Estado desdobre o resultado dessa convenção em políticas públicas, foi preciso que se produzisse campanhas de sensibilização de homens e mulheres, pressionando-se os organismos governamentais (Maier, 1992).

A cidadania deve estar presente em todo e qualquer espaço social para que homens e mulheres, pobres, negros, entre outros, possam desfrutar de sua condição de cidadão. "Pelo menos é esta a luta da perspectiva feminista, que busca ser a mais holística possível" (Saffioti, 1999: 86).

\section{O Papel do Estado}

0 investimento em programas públicos de proteção à mulher, que teve um grande impulso $\mathrm{a}$ partir da volta da eleição para governadores em 1982, após quase duas décadas de um regime de exceção, implementaram políticas que foram mais intensificadas nas duas últimas décadas. A condenação do agressor, sem a possibilidade de transformação da pena em multa ou cestas 
básicas, além do apoio jurídico às mulheres, assistência social, abrigo temporário e outras ações, foram mudança que ocorreram nesse período.

Apesar da promulgação da lei Maria da Penha1, associado aos esforços seguidos pelas organizações políticas, pelas "Organizações Não-Governamentais" ligadas aos movimentos feministas ou de mulheres, a luta ainda se faz necessária contra essa mancha na sociedade brasileira, que é a violência contra a mulher, que se mantém, internacionalmente, em níveis vexatórios.

Os principais programas implementados pelo Estado focam no atendimento às mulheres vítimas da violência doméstica. Todos estes programas são indispensáveis para o enfrentamento da questão em sua complexidade, todavia, para se alcançar um avanço nessa luta, é imprescindível que haja investimento na formação de mulheres e homens. Isto quer dizer que a educação de meninas e meninos, construindo com eles relações de gênero de caráter democrático, igualitário, ganha importância, e, consequentemente, a escola e o currículo.

Os processos macropolíticos, em geral, atuam no sentido de garantir a reprodução social, mas, em determinadas situações, eles também podem desempenhar um papel na aceleração das transformações sociais. A criação, pelo governo federal, na primeira gestão petista, da Secretaria Especial de Políticas para as Mulheres, é um exemplo interessante para ilustrar como os processos macropolíticos podem contribuir as mudanças necessárias.

Em geral, uma política pública que atenda a interesses de grupos não-hegemônicos é resultado de pressões desses grupos organizados, que potencializam os processos micropolíticos, para alcançarem as mudanças esperadas. Entretanto, a promulgação de uma lei, não significa que necessariamente as políticas funcionarão, na maioria de casos como esse, tem que se investir na luta para garantir a implementação efetiva da política, pois é sabido que qualquer política pública implementada por pressões dos segmentos não-hegemônicos contará sempre com fortes resistências para sua efetiva implementação. 0 caso da lei "Maria da Penha" ilustra bem o que foi dito.

Em 2007, na cidade de Botucatu/SP, uma jovem, médica, registrou uma queixa em uma Delegacia de Polícia da cidade, dizendo ter sido ameaçada de morte pelo ex-namorado, ele teria tentado incendiar sua casa. 0 resultado deste caso é que, após alguns meses, a jovem foi barbaramente assinada com uma marreta, juntamente com sua mãe e seu pai. (Vaz, 2012: 115).

Este acontecimento se deu, já, na vigência da Lei Maria da Penha, o que mostra que as mudanças sociais não ocorrem apenas porque a legislação mudou, especialmente quando se trata de relações de poder que estão cristalizadas, tal qual a dominação masculina, que contamina todas as esferas e instituições sociais, dentre elas a própria justiça.

1 Lei n. 11.340 de 7 de agosto de 2006. Cria mecanismos para coibir a violência doméstica e familiar contra a mulher, nos termos do § 8o do art. 226 da Constituição Federal, da Convenção sobre a Eliminação de Todas as Formas de Discriminação contra as Mulheres e da Convenção Interamericana para Prevenir, Punir e Erradicar a Violência contra a Mulher; dispõe sobre a criação dos Juizados de Violência Doméstica e Familiar contra a Mulher; altera o Código de Processo Penal, o Código Penal e a Lei de Execução Penal; e dá outras providências. 
A simples promulgação da lei que enquadra o agressor, e que pode levá-lo à reclusão, não é uma garantia concreta de segurança às mulheres, já que uma parcela significativa das mulheres vítimas de violência, ainda depende economicamente do marido. Nos casos em que as mulheres estão em condições de viver de forma independente, ainda assim ela corre risco de ser vítima de formas de violência, por parte de seu companheiro ou ex-companheiro, que pode chegar à morte.

Para Heleieth Saffioti e Suely Almeida (1995) é absolutamente necessário que os movimentos sociais acompanhem o desenvolvimento das políticas vinculados à discriminação positiva. Deixá-las apenas aos cuidados do Estado, poderá servir apenas como letra morta. Para que a justiça se concretize, é fundamental que a pressão junto aos setores do Estado responsáveis pelos distintos programas não esmoreça.

Mesmo correndo o risco de levar os grupos a uma certa acomodação política, as ações afirmativas abrem fendas nos organismos de controle, e, por um acúmulo nos processos sociais, que fluem e refluem, podem possibilitar mudanças no plano microssocial, onde a vida transcorre concretamente (Saffioti \& Almeida, 1995).

O processo de conformação social não é uma determinação mecânica, que estaria além das possibilidades de uma ação crítica. Mesmo em espaços em que as formas de controle são grandes, sempre é possível um passo na direção de novas formas de sociabilidade. Jamais veremos um proprietário de canal de TV defender posições revolucionárias, mas seus funcionários, em algum momento, poderão perceber pequenas ou grandes fissuras, onde poderão expressar sua visão de mundo, mesmo que de maneira camuflada, indireta, inclusive para escapar do controle e, obviamente, das retaliações, tendo a demissão em seu horizonte como a forma máxima de retaliações.

Veja-se o caso das telenovelas, tão presentes nos lares brasileiros, e com incrível capacidade de influenciar a visão de mundo e, por conseguinte, o comportamento da população. A homossexualidade tem sido objeto constante das telenovelas, que a tem enfocado, não de forma caricatural, mas muito mais perto das relações reais, mostrando o lado humano das personagens. Ao contrário dos programas humorísticos, que se utilizam de elementos caricaturais, que tem por fim o aumento das práticas discriminatórias.

Quando uma telenovela traz elementos críticos à "normalidade" da sociedade, ela cria espaço de discussões entre as famílias, em escolas, no trabalho e entre amigos. Certamente, grupos de meninas e meninos que se identificam como pertencentes à comunidade LGBTQIA+, deverão se beneficiar deste processo, e posto, a partir daí, novos elementos em sua própria vida e na de sua família. Este processo é explicado, no senso comum, com se as telenovelas estivem estimulando este "tipo" de comportamento.

As telenovelas também tomaram a violência contra a mulher como objeto de problematização. Seria interessante uma pesquisa que procurasse aferir a influência da telenovela na vida prática das pessoas, como descobrir se por ocasião de sua transmissão, com cenas de violência doméstica, houve crescimento na quantidade de denúncias contra agressão praticada pelo marido, namorado ou ficante. 


\section{A Escola, as Mulheres e os Direitos Humanos}

É preciso que o sistema educacional dê condições para que todos conheçam a gênese das relações estruturais de dominação, para que assim possam construir, de fato, um mundo digno, humano, amoroso e fraterno para todos, sem distinção de nenhuma espécie.

Mas, ao que nos parece, as questões ligadas à violência contra a mulher não têm sido satisfatoriamente tratadas na escola. Movimentos que se autodenominam conservadores, apoiados nos diferentes níveis de governo, têm empreendido esforços no sentido de impedir que o currículo escolar trate de questões fundamentais para o comportamento humano. As discussões de gênero, de sexualidade, são aquelas que suscitam maior preocupação.

Esses grupos que fazem pressão sobre a escola, sobre as professoras e professores, entendem que essas questões devem ser tratadas apenas pela família, e, talvez, pelas igrejas. 0 fato é que esse modelo, defendido por esses grupos, é o que produziu a sociedade brasileira contemporânea, que está entre as que mais cometem violência contra as mulheres, gays, travestis, transexuais.

Para Elizabeth Maier (1992) as universidades devem incluir no currículo a disciplina de Direitos Humanos, e, esta, deve tratar das também das questões da mulher. Devem promover pesquisas e seminários sobre os diferentes temas, para possibilitar a divulgação e o entendimento dos direitos e sua implicação na vida cotidiana. Isso, de certo modo, em partes dos cursos de formação, vem acontecendo; em alguns casos como projeto pedagógico do curso, em outros apenas como iniciativa de professoras e professores, e, muitas vezes, à revelia da coordenação do curso.

Eva Blay (2003: 96) é outra defensora dessa discussões nos currículos escolares e universitários, visto trata-se de importantes temáticas para a vida das pessoas. Entretanto, a autora problematiza essa possibilidade:

Nos programas escolares - desde o Ensino Fundamental até o universitário precisa haver a inclusão da dimensão gênero mostrando como a hierarquia existente na cultura brasileira de subordinação da mulher ao homem traz desequilíbrios de todas as ordens - econômico, familiar, emocional e incrementa a violência. Mas a escola não pode ficar isolada de um processo amplo de transformação para alcançar a equidade de gênero. 0 que pode fazer uma professora, de qualquer nível da escala educacional, se ela própria é violentada? O que pode ensinar um professor que é um violador? O que pode fazer a escola se estiver desligada de um processo de transformação cultural?

As questões colocadas por Blay continuam extremamente atuais. Os cursos de licenciatura das universidades privadas, especialmente os de Pedagogia, que são aquelas que formam a maioria dos educadores, têm recebido uma quantidade significativa de pessoas com uma perspectiva conservadora, orientadas por uma direção religiosa, que chegam preparadas para resistirem ao que chamam de "ideologia de gênero". Possuem uma compreensão bastante superficial e manipulada das questões de gênero e de sexualidade, e manifestam sua resistência silenciosamente, ignorando a discussão, ou expõem a sua perspectiva para na aula. No segundo caso, traz, ao mesmo tempo, a possibilidade de problematização dessas posições, que pode proporcionar uma ação dialógica, que poderá produzir resultados mais eficazes no processo de transformação. Já no primeiro caso, não há qualquer possibilidade de mudança. 
Este trabalho de formação é complexo, requer uma boa capacidade didática, de alteridade e de diálogo entre os educadores e os educandos. Bell Hooks (2013) fala do desafio de professoras e professores de dialogar de forma eficaz, produzindo efeitos transformadores, diante de um grupo heterogêneo de pessoas etnicamente diversificadas, com diferentes origens sociais, que não compartilhem a mesma variação linguística, o mesmo nível de compreensão, a mesma habilidade de comunicação e as mesmas preocupações.

Para nos confrontarmos mutuamente de um lado e do outro das nossas diferenças, temos de mudar de ideia acerca de como aprendemos; em vez de ter medo do conflito, temos de encontrar meios de usá-lo como catalisador para uma nova maneira de pensar, para o crescimento (Hooks, 2013: 154).

Fabíola Rohden (2009) relata uma experiência piloto de formação a distância com profissionais da educação básica de redes estaduais e municipais do país, ocorrida em 2006, produzida a partir da articulação entre a Secretaria Especial de Políticas para Mulheres, a Secretaria Especial de Políticas para promoção da Igualdade Racial, o Ministério da Educação, o British Council e o Centro Latino-Americano em Sexualidade e Direitos Humanos da Universidade Estadual do Rio de Janeiro, cuja temática era: gênero, sexualidade, orientação sexual e relações étnico-raciais.

Embora estejamos em um outro momento político de nossa história, mais estreito, do ponto de vista de práticas educativas civilizatórias, ainda há a possibilidade de elaboração de projetos políticos pedagógicos de unidades escolares das redes públicas, além da própria autonomia docente (Silva, 2007). O projeto citado traz como fundamentos elementos que são indispensáveis para práticas pedagógicas progressistas, que possam efetivamente contribuir para a formação inicial e continuada de docentes (Rohden, 2009: 161-162):

1. diferenças de gênero, de orientação sexual, de raça/etnia devem ser respeitadas e valorizadas, não devendo ser utilizadas como critério de exclusão social e política;

2. é fundamental manter uma perspectiva não-essencialista em relação às diferenças, procurando desenvolver uma postura crítica em relação aos processos de naturalização ou biologização, que acabam por transformar diferenças em desigualdades;

3. discriminações baseadas em raça/etnia, gênero e sexualidade estão imbricadas na vida social e na história de diferentes sociedades, necessitando por isso uma abordagem conjunta e transversal. Ou seja, discriminação em relação às mulheres articula-se à discriminação em relação aos que são sexualmente atraídos por pessoas do mesmo sexo ou ainda que discursos racistas possam utilizar características socialmente atribuídas ao feminino para inferiorizar negros/as, indígenas ou outros grupos considerados inferiores;

4. a formulação de leis anti-discriminação não é suficiente para fazer cessar ações violentas e intolerantes em relação às diferenças de gênero, de raça e orientação sexual, sendo para isto fundamental privilegiar ações que visem à transformação das mentalidades e das práticas sociais;

5. a escola, embora tenha se constituído historicamente como espaço de reprodução de preconceitos, é local estratégico para o processo de transformação e deve cumprir sua missão de formar pessoas dotadas de espírito crítico; 
6. o estatuto das diferenças de gênero, de raça e de orientação sexual é um debate aberto envolvendo delicadas questões morais, sendo que o curso não deve, portanto, pretender divulgar a "verdade" sobre tais diferenças pela adoção de qualquer tipo de cartilha ou doutrina. Nesse sentido, o fundamental é propiciar que os alunos e as alunas compreendam as implicações éticas das diferentes posições em jogo e construam sua própria opinião nesse debate;

Assim...

Vê-se que a relação entre a educação escolar e o desenvolvimento real da cidadania passa, necessariamente, pelo conhecimento dos ideais e dos contextos dos direitos humanos e das relações políticas que a cercam. A problematização dos privilégios e, portanto, o estudo das relações de poder que os garantem, é fator decisivo na compreensão crítica dos direitos humanos e de uma vida cidadã para todos.

A escola precisa tomar o tema dos direitos humanos em todas as suas dimensões, e ser elemento contínuo de formação de educandos e de educadores. Essa formação precisa ser sempre renovada para que se possa aperfeiçoar a cada dia as questões teóricas e metodológicas, inclusive para se propor formas de enfrentamento às ações de resistência de grupos de professoras e professores, de estudantes, que não se sensibilizam com os problemas que advém de uma cidadania de segunda classe para certos grupos sociais, enquanto outros se cobrem de privilégios.

O trabalho terá de ser necessariamente amplo e gigantesco, e contar, preferencialmente, com o envolvimento de secretarias de educação de municípios e de estados, além do Ministério da Educação, para que se possa lançar de fato um grande movimento à favor da democratização dos direitos humanos, à favor do avanço do processo civilizatório.

Apesar da importância do envolvimento de todas essas instituições anteriormente citadas, não se deve esquecer, jamais, que o trabalho é realizado efetivamente por educadoras e educadores, mesmo contra políticas curriculares ou movimentos policialescos conservadores (Silva, 2011). Ainda, assim, é possível fazer a diferença na vida de meninas e meninos, crianças e jovens, a fim de construírem uma vida digna, solidária e com um movimento crescente em direção a ampliação cada vez maior de uma liberdade concreta. 


\section{Referências Bibliográficas}

Blay, Eva A. (2003). Violência contra a mulher e políticas públicas. Estudos avançados, 17 (49).

Facio, Aida. (1991). Sexismo en el derecho de los derechos humanos. Em CLADEM Mujer y derechos humanos en America latina. (pp. 17-18.) Lima: CLADEM,

Facio, Alda. (2017). ¿Igualdad y/o Equidad? Nota para la igualdad, 1. Una agenda de gênero para el América Latina y el Caribe. Acessado em 12 de Janeiro de 2019, de: http://www.americalatinagenera.org/es/documentos/centro gobierno/FACT-SHEET-1DQEH2707.pdf

Freire, Nilcéa. (2007). Conferência. In: TAQUETTE, Stella R. (Org.). Violência contra a mulher adolescente/jovem. (pp. 19-22). Rio de Janeiro: EdUerj.

Hooks, Bell. (2013). Ensinando a transgredir: a educação como prática da liberdade. São Paulo: Martins Fontes.

Lacarde, Marcela. (2017). Identidad de Género y Derechos Humanos: La construcción de las humanas. Programa Oficial de Posgrao en Estudos de Xénero da Universidade de Vigo. Acessado em 11 de abril de 2019, de: http://webs.uvigo.es/xenero/profesorado/marcela lagarde/construccion humanas.pdf>.

Maier, Elizabeth. (1992). La mujer frente a los Derechos Humanos. Política y Cultura. Otoño, n. 1, Universidad Autónoma Metropolitana Xochimilco, Distrito Federal, México, p. 35-47. Acessado em 11 de abril de 2019, de: http://148.206.107.15/biblioteca digital/estadistica.php?id host=6\&tipo=ARTICULO\&id=35 92\&archivo $=8-238-$ 3592flq.pdf\&titulo=La\%20mujer\%20frente $\% 20 a \% 2010$ s $\% 20$ derechos $\% 20$ humanos

Organização das Nações Unidas (ONU). (2017). Declaração universal dos Direitos humanos. Acessado em 11 de abril de 2019, de: http://www.redeblh.fiocruz.br/media/decl d human.pdf

Ríos, Marcela L. de los. (2017). ¿A qué llamamos feminicidio? Programa Oficial de Posgrao en Estudos de Xénero da Universidade de Vigo. Acessado em 10 de outubro de 2017, de: http://webs.uvigo.es/xenero/profesorado/marcela lagarde/feminicidio.pdf

Rohden, Fabíola. (2009). Gênero, sexualidade e raça/etnia: desafios transversais na formação do professor. Cadernos de Pesquisa, 39 (136), 157-174.

Saffioti, Heleieth I. B. (2009). Ontogênese e filogênese do gênero: ordem patriarcal de gênero e a violência masculina contra mulheres. Série Estudos e Ensaios / Ciências Sociais / FLACSO. Brasil, junho. Acessado em 21 de maio de 2019, de: http://flacso.org.br/?publication=ontogenese-e-filogenese-do-genero-ordem-patriarcal-degenero-e-a-violencia-masculina-contra-mulheres

Saffioti, Heleieth I. B. \& Almeida, Suely S. de. (1995). Violência de gênero: Poder e Impotência. Rio de Janeiro: Revinter. Acessado em 15 de abril de 2019, de: https://drive.google.com/file/d/1y88VN64tpVjALrry4c PSo8ivnHYUjgq/view

Saffioti, Heleieth I. B. (2000). Exploração sexual de crianças. In: Amaria Amélia Azevedo, \& Viviane Guerra. (Orgs.). Crianças vitimizadas: a síndrome do pequeno poder. (pp. 49-95.). São Paulo: Iglu.

Saffioti, Heleieth I. B. (2004). Gênero, patriarcado, violência. São Paulo: Perseu Abramo. Acessado em 12 de naio de 2019,de: 
https://edisciplinas.usp.br/pluginfile.php/1741437/mod resource/content/1/G\%C3\%AAne ro\%2C\%20Patriarcado\%2C\%20Viol\%C3\%AAncia\%20\%20\%28livro\%20completo\%29.pdf

Silva, Alessandro Soares da. (2006). Marchando pelo Arco-Íris da Política: a Parada do Orgulho LGBT na construção da consciência coletiva dos movimentos LGBT no Brasil, Espanha $e$ Portugal. Tese de Doutorado. Pontifícia Universidade Católiica de São Paulo, São Paulo. Acessado em 25 de outubro de 2019, de: https://sapientia.pucsp.br/handle/handle/17164

Silva, Alessandro Soares da. (2007). Direitos Humanos e Lugares Minoritários: um convite ao pensar sobre os processos de exclusão na escola. Em: Ministério da Educação. Programa Ética e Cidadania: construindo valores na escola e na sociedade. Acessado em 19 de maio de 2019, de: http://portal.mec.gov.br/seb/arquivos/pdf/Etica/11 soares.pdf

Silva, Alessandro S. (2009). Contribuições dos Movimentos Sociais para a Desprivatização da Ética na Perspectiva da Psicologia Política. Flávia Mori Sarti, \& Gislene Aparecida dos Santos. (Org.). Ética, Pesquisa e Políticas Públicas. São Paulo: Rubio. Acessado em 19 de maio de 2019, de: https://www.researchgate.net/publication/344041671 Contribuicoes dos Movimentos So ciais para a Desprivatizacao da Etica na perspectiva da Psicologia Politica

Silva, Alessandro Soares da. (2011). Políticas públicas, educação para os direitos humanos e diversidade sexual. Trivium - Estudos Interdisciplinares, 3(2), 58-72. Acessado em 14 de março de 2019, de: http://pepsic.bvsalud.org/scielo.php?script=sci arttext\&pid=S2176$48912011000200007 \& \operatorname{lng}=\mathrm{es} \& \mathrm{t} \operatorname{lng}=\mathrm{pt}$

Silva, Alessandro Soares da., \& D’Addio, Thomaz Ferrari. (2012). Homofobia, Violência e Direitos Humanos. Em Marco Almeida, Alessandro Silva \& Felipe Corrêa. Psicologia Política: Debates e embates de um campo interdisciplinar. São Paulo: EACH Edições. Acessado em 19 de maio de 2019 ,

de:

https://www.researchgate.net/publication/344088028 Homofobia Violencia e Direitos H umanos

Silva, Alessandro Soares da., \& Ortolano, Fabio. (2015). Narrativas psicopolíticas da homofobia. Trivium - Estudos Interdisciplinares, 7(1), 01-18. Acessado em 19 de maio de 2019, de: https://dx.doi.org/10.18370/2176-4891.2015v1p1

Teles, Maria Amélia A. e Melo, Mônica. (2003). O que é violência contra a Mulher. São Paulo: Brasiliense.

Vaz, Antonio Carlos. (2005). Entra mãe e sai mulher? As possibilidades de redefinição do papel feminino com base em experiências públicas na escola. Psicologia Política, 3(5), 121-140. Acesado em 12 de fevereiro de 2019, de: https://abpsicologiapolitica.files.wordpress.com/2019/06/rev.-psi-politica-v3n5.pdf

Vaz, Antonio Carlos. (2012) Violência contra as mulheres: estudo com adolescentes no município de Guarulhos. Tese de Doutorado. Universidade Estadual Paulista "Júlio de Mesquita Filho", Araraquara. Acessado em 19 de maio de 2019, de: http://wwws.fclar.unesp.br/agendapos/ciencias sociais/2790.pdf

Recebido em 22/05/2019. 